\title{
Exploring the connection between transdisciplinary co-production and urban stream sustainability solutions: A case study at an urban stream management symposium
}

\section{R. Patrick Bixler ( $\sim$ rpbixler@utexas.edu )}

UT Austin: The University of Texas at Austin https://orcid.org/0000-0003-0515-0967

Amy Belaire

The Nature Conservancy

Kasey Faust

UT Austin: The University of Texas at Austin

Mateo Scoggins

City of Austin

Ana Gonzalez

City of Austin

\section{Research Article}

Keywords: urban sustainability, co-production, transdisciplinary research, community engagement

Posted Date: May 14th, 2021

DOl: https://doi.org/10.21203/rs.3.rs-481659/v1

License: (c) (i) This work is licensed under a Creative Commons Attribution 4.0 International License.

Read Full License

Version of Record: A version of this preprint was published at Urban Ecosystems on March 23rd, 2022. See the published version at https://doi.org/10.1007/s11252-022-01226-7. 


\section{Abstract}

Urban sustainability challenges are complex, impacting a wide range of stakeholders. In seeking solutions to sustainability problems, we ask in this case study: does team formation-specifically, single-, multi- or trans-disciplinary teams- impact the process and perceived efficacy of outcomes? It is commonly accepted that sustainable solutions must integrate scientific knowledge from multiple disciplines, coupled with community stakeholder ideas, norms, and practices in ways that link knowledge generation to decision-making and action. However, professionals often express barriers in meaningfully co-producing solutions across disciplinary or departmental boundaries and urban community engagement has traditionally informed, rather than empowered, local citizens. Because of these and other barriers, little empirical work has been conducted in ways that link insights from team science and community engagement to the co-production of knowledge for urban sustainability. Using case study data collected at the 5th Symposium for Urbanization and Stream Ecology (SUSE5), held in February 2020, we explored the impact of bringing different types of teams together to generate solutions to realworld "wicked problems" surrounding urban streams in Austin, Texas. We found that the solutions generated by trans-disciplinary teams-i.e., teams which include multiple disciplines and community members-were on average rated higher by their peers than solutions from single- or multi-disciplinary teams. However, the self-ratings of intra-team interactions of transdisciplinary teams had the highest variability. The findings from this limited, but novel and unique case study highlight the link between diverse actors working to solve complex problems in the service of community and policy change but also the challenges of transdisciplinary teams co-producing knowledge. A better understanding of these challenges can inform institutions and agencies employing a community-engaged process to solve urban sustainability challenges.

\section{Introduction}

Urbanization is one of the most significant trends of the twenty-first century, with nearly 68 percent of the world's population expected to live in cities by 2050 (United Nations 2018). One projection suggests that, in just the next decade alone, approximately 2.6 billion more people will be added to world cities (Bai et al. 2018). The environmental implications of rapid urbanization are profound and far reaching, with the impacts often outpacing population growth. Cities are both a driver and main bearer of the greatest social and environmental challenges of the day - climate change, public health, resource availability - at local and regional scales and across the globe (Grimm et al. 2008). Addressing these urban challenges requires balancing multiple, often conflicting, objectives with limited resources: equitable communities, economic development, sufficient food, water and energy, opportunities for recreation and renewal, and reduced risks to disasters (Bixler et al. 2019b; Keeler et al. 2019).

Yet, in response to the challenges and multidimensional demands, urbanization also brings about a unique window of opportunity for knowledge co-production and the implementation of innovative sustainable solutions. Urban areas are the grounds of experimenting not only with new technologies but also with new systems-level approaches towards livability, sustainability and resilience (Bai et al. 2016). 
There is broad agreement that to solve contemporary urban challenges and build resilient communities, researchers, policymakers, practitioners and other city stakeholders need to strengthen partnerships and produce knowledge together (Bai et al. 2018a). Academic and non-academic partnerships and stakeholder engagement intersect at the idea of co-production. Co-production is a framework to address the complex nature of contemporary sustainability challenges by co-producing knowledge between scientists and stakeholders (Norström et al. 2020a). Co-production is a way to produce new knowledge with a clear normative objective to support societal change (Wyborn et al. 2019). The current concept converged from public administration, science and technology studies, and sustainability studies suggests that for knowledge to be actionable, the production of science should occur collaboratively to define important questions, identify relevant evidence, and co-create convincing forms of argument (Miller and Wyborn 2020).

Interestingly, the intersection of co-production and team science has been understudied. Team science has grown in recognition and importance as it has become more collaborative, interdisciplinary, and networked in the 21st century (Bixler et al. 2019a; Milojević 2014). Team science emerged from the necessity of solving complex problems by working together across disciplinary boundaries. Related, coproduction has expanded this conception to going beyond the academic and non-academic boundary. One of the high-priority directions outlined for team science is examining interpersonal processes and leadership styles on scientific collaboration (Milojević 2014; Nancarrow et al. 2013; Fiore 2008). Interdisciplinary teamwork, and scientific co-production in transdisciplinary teams that include nonacademic stakeholders and community members, require complex social and cognitive processes. Constructs such as trust, openness, communication, collaboration, conflict, and shared cognitive models become very important (Cooke et al. 2015; Cassidy and Stanley 2019; White et al. 2019; Delice et al. 2019; Nagy et al. 2020).

The intersection of team science, co-production, and urban sustainability is broadly supported, however, evidence that directly connects a co-production process to outcomes is limited. Moreover, evidence that demonstrates a co-production process performs different than, or better than, a more traditional siloed or pure disciplinary team is lacking. We address this gap through a case study of the 5th Symposium of Urban Stream Ecology (SUSE5).

\section{Background}

The SUSE5 was held in Austin, Texas in February of 2020. The goal of the symposium, building upon the previous four meetings (SUSE 1, Victoria 2003; SUSE 2, Utah 2008; SUSE 3, Oregon 2014; SUSE 4, North Carolina 2017), was to advance understanding of how urbanization impacts aquatic ecosystems and the effects of management interventions in urban landscapes. Over the course of SUSE meetings, participation has diversified from primarily scientists in a few disciplines (stream ecology, biology) to an array of scientists across the fields of environmental, social, and political science, stream restoration and management practitioners, non-profit community groups, and even local citizens. 
SUSE5 used an intentionally designed, team-based collaboration to work on ideating solutions for four "wicked" stream problems in Austin, TX USA. Case studies, compiled by City of Austin staff, represented documented problem sites that were not already under planning and design and had common underlying issues: flooding and erosion, degraded habitat, poor water quality, the lack of obvious stormwater management opportunities, tight stream/floodway corridors, and local community involvement.

The symposium, designed to address "real world urban stream problems", provided a unique opportunity to think about urban sustainability solutions that integrate scientific knowledge from multiple disciplines alongside community ideas, norms, and practices; i.e., the process of co-production (Norström et al. $2020 \mathrm{~b}$ ). We reviewed the literature on co-production and team science and developed a conceptual model on what conditions have been empirically reported to contribute to successes and failures in successful teams (Salas et al. 2005, 2015). We combine insights from this body of research with success factors associated with co-production and transdisciplinary research to test some hypothesis about coproduction in our short-term case study.

\section{Methods}

Each of the four "real world urban stream problem" locations were assigned three teams of approximately 10-12 SUSE attendees (12 teams total). Teams were intentionally structured either as disciplinary (e.g., all biologists), multidisciplinary (e.g., a combination of biologists, engineers, planners, etc.), or as coproduction, transdisciplinary teams that included community members. The transdisciplinary teams included a mix of professional backgrounds as well as several members of the local community and/or historically underrepresented stakeholder groups. A key goal of this intentional team structure design was to document the potential differences in the quality of the process and the conceptual solutions across team diversity (e.g., did teams including community representatives produce concepts that were more community-centric than teams that lacked community representation?). Each team was assigned a facilitator and worked throughout the conference together during four work sessions. The work sessions were phases of each work session included: (1) team formation and problem identification, (2) problem structuring including identifying objectives and values to solve for, (3) visiting the site in a field trip, and (4) conducting analysis, refining suggested solutions and preparing a presentation. These work sessions were structured around the primary functions of the research process: problem identification, problem analysis, and embeddedness of the results in context (Pohl and Hadorn 2007; Pohl 2008; Lang et al. 2012; Bixler et al. 2019a). These sessions were sequential throughout the SUSE symposium and correspond to stages of the transdisciplinary research process, hereafter referred to as "stages". Survey data about team process was collected after stage 1,2 , and 4 .

The program design of SUSE5 was a unique opportunity to test hypotheses that can help inform the principles and design of co-production for urban resilience. The hypotheses considered were:

$\mathrm{H} 1$ : The solutions presented by the co-production teams will be higher rated by peers.

H2: The process of the co-production teams will be rated higher by team members. 
H3: A higher rated process (internal ratings) will be correlated to higher rated solutions (peer ratings)

At the end of each stage, conference participants were given a brief paper survey that used a seven-point Likert scale from strongly disagree to strongly agree and asked questions related to the process and quality of team interaction. Surveys were anonymous but participants were asked to provide their team number to map to which of the four wicked problems was assigned to that group and what the team composition was (e.g., single-disciplinary). Example questions include: "In general, there was equal consideration of ideas in our team" and "In general, there was equitable input on decisions that were made". Other seven-point Likert questions ranged from "never" to "every time". Example questions here include: "At your site, to what extent is your understanding of the problem to be addressed aligned with your other team members"? Table 1 includes a summary of questions, item means, and standard deviation. 
Table 1

The "process" survey questions.

\begin{tabular}{|c|c|c|c|c|}
\hline $\begin{array}{l}\text { Q } \\
\text { No. }\end{array}$ & Question & Range & Mean & SD \\
\hline 1.1 & $\begin{array}{l}\text { The members of this team utilize diverse perspectives to generate } \\
\text { discussion }\end{array}$ & $3-7$ & 5.86 & 0.78 \\
\hline 1.2 & $\begin{array}{l}\text { As a team, we generate ideas that are much more diverse than those } \\
\text { we could develop as individuals }\end{array}$ & $3-7$ & 6.2 & 0.75 \\
\hline 1.3 & $\begin{array}{l}\text { To what extent did you share information relevant to your } \\
\text { understanding of the case site with others during this session }\end{array}$ & $1-7$ & 4.63 & 1.25 \\
\hline 1.4 & $\begin{array}{l}\text { To what extent did you receive information from a different } \\
\text { perspective from others during this session? }\end{array}$ & $3-7$ & 5.35 & 0.86 \\
\hline 2.1 & $\begin{array}{l}\text { I feel comfortable sharing limits or gaps in your knowledge to my } \\
\text { team }\end{array}$ & $2-7$ & 5.85 & 1.01 \\
\hline 2.2 & I feel comfortable sharing my input and thoughts & $2-7$ & 5.99 & 0.92 \\
\hline 2.3 & I feel that my team is open to everyone's perspectives and thoughts & $2-7$ & 6.01 & 0.97 \\
\hline 2.4 & In general, I find my team is open to constructive feedback & $3-7$ & 5.93 & 0.9 \\
\hline 2.5 & $\begin{array}{l}\text { Our team is able to capitalize on the strengths of different team } \\
\text { members }\end{array}$ & $2-7$ & 5.59 & 1.06 \\
\hline 2.6 & Please evaluate the collaboration within your team & $4-7$ & 5.62 & 0.84 \\
\hline 3.1 & In general, there was equal consideration of ideas in our team & $2-7$ & 5.80 & 0.85 \\
\hline 3.2 & $\begin{array}{l}\text { In general, there was equitable input on the decisions that were } \\
\text { made }\end{array}$ & $1-7$ & 5.64 & 0.91 \\
\hline 3.3 & $\begin{array}{l}\text { At your site, to what extent is your understanding of the problems to } \\
\text { be addressed aligned with that of other team members? }\end{array}$ & $3-7$ & 5.35 & 0.81 \\
\hline 3.4 & $\begin{array}{l}\text { At your site, to what extent is your understanding of the components } \\
\text { of the solution aligned with that of other team members? }\end{array}$ & $2-7$ & 5.28 & 0.83 \\
\hline
\end{tabular}

Each team concluded the SUSE meeting with a brief presentation that provided an overview of their work session outcomes, including proposed solutions for their case study site. During this presentation that summarized the culmination of team efforts, all conference participants were asked to rate the solutions to the urban stream problem presented by other teams. Each attendee ranked other groups on a 5-point Likert scale from strongly disagree to strongly agree with a neutral option (see Table 2). 
Table 2

The "solution" survey questions.

\begin{tabular}{|llccc|}
\hline $\begin{array}{l}\text { Q } \\
\text { No. }\end{array}$ & Question & Range & Mean & SD \\
\hline & The solution presented seems... & & & \\
\hline S.1 & $\quad \ldots$..realistic and feasible & $1-5$ & 4.16 & 0.69 \\
\hline S.2 & $\quad \ldots$...ike it has benefits that would outweigh the costs & $2-5$ & 4.04 & 0.7 \\
\hline S.3 & $\quad \ldots$...ike it could be sustainable over the long-term & $2-5$ & 4.02 & 0.71 \\
\hline S.4 & $\begin{array}{l}\text {...like it would be seen as a benefit by residents in nearby } \\
\text { neighborhoods }\end{array}$ & $1-5$ & 4.19 & 0.78 \\
\hline S.5 & $\quad$...innovative and creative & $1-5$ & 4 & 0.85 \\
\hline
\end{tabular}

The ideas generated from the meeting have been shared with City staff, who have followed up with community representatives, conducted staff interviews, etc. to continue the evaluation of potential solutions within the City's project development structure.

\section{Results}

This case study provided an interesting venue to test some ideas about co-production, particular as to how transdisciplinary teams, that include community members engaged throughout each stage of the process, compare and contrast to disciplinary and multi-disciplinary teams in process and solutions.

\section{The solutions (Hypothesis 1)}

Hypothesis 1 explores whether the solutions presented by the co-production teams will be higher rated by peers. Each of the 12 teams presented their solution on the last day of the conference. All conference attendees rated the solution presented by each team that was not their own. The solutions presented by the transdisciplinary teams (that included community members as well as those from different profession disciplines) were rated higher by their peers than the other groups (see Figure 1).

An ANOVA (analysis of variance) test confirms statistical significance of the difference between the variances of the solution ratings and the different groups $(F(2,9)=0.4138, p=.03)$.

\section{The Process (Hypothesis 2)}

Hypothesis 2 is that the process of the co-production teams will be rated higher by (internal) team members. On average, we found that the multidisciplinary teams had the highest average rating (5.67), followed by disciplinary teams (5.61), and then the transdisciplinary teams (5.60). Figure 2 illustrates these differences. 
The differences between the groups were not statistically significant $(F(2,9)=0.0112, p=.881)$. Because we collected data at three time periods - that conceptually correspond to the different phases of team formation, problem identification and structuring, and problem analysis - we can identify trends across those phases (Table 3 and Figure 3 ). Across the groups, the process was rated higher after the problem identification and structuring (stage 2 ) of activities.

\section{Table 3. Mean ratings and standard deviations by group and by stage}

\begin{tabular}{|c|c|c|c|c|}
\hline $\begin{array}{l}\text { Stage } 1 \\
\text { (problem } \\
\text { definition) }\end{array}$ & $\begin{array}{l}\text { Stage } 2 \\
\text { (problem } \\
\text { structuring) }\end{array}$ & $\begin{array}{l}\text { Stage } 3 \\
\text { (analysis) }\end{array}$ & $\begin{array}{l}\text { Combined process ratings } \\
\text { (average of three stages) }\end{array}$ & \\
\hline \multirow[t]{2}{*}{ Disciplinary } & 5.52 & 5.96 & 5.36 & 5.61 \\
\hline & $(.17)$ & $(.09)$ & $(.25)$ & (.13) \\
\hline \multirow[t]{2}{*}{ Multidisciplinary } & 5.49 & 5.90 & 5.63 & 5.67 \\
\hline & $(.05)$ & $(.16)$ & $(.14)$ & $(.06)$ \\
\hline \multirow[t]{2}{*}{ Transdisciplinary } & $5.55(.36)$ & 5.67 & 5.59 & 5.60 \\
\hline & & $(.55)$ & $(.26)$ & (.33) \\
\hline
\end{tabular}

Combing the analysis across team type and across session (Figure 3), we observe a "process peak" in stage two for the disciplinary and multidisciplinary teams with significant variability across the stages for the transdisciplinary teams.

\section{Linking the Process and the Solution (Hypothesis 3)}

Our third hypothesis is that groups with a higher rated process (internal team ratings) will have higher rated solutions (peer ratings based on presentations). We found little to no evidence of this in our case study. The results of a Pearson correlation indicated that there was a non-significant negative association between the team process ratings and the solution ratings $(r(10)=-.02, p=.9477)$. Regression results (model 1 in Table 4) reaffirm the weak and statistically non-significant relationship between team process and solution ratings.

However, there is a positive association between being a transdisciplinary team and the overall solution rating score (Table 4, Model 2). Relative to transdisciplinary teams, being a multidisciplinary team has a $-0.31(0.15, p<.10)$ effect on solution rating and being a disciplinary team has a $-0.45(0.15$, $p<.05)$ effect on solution rating. 


\section{Table 4. SUSE Solution Rating, Team Composition, and Team Process}

Dependent variable:

Solution Rating Score

(1)

(2)

(3)

Team Process Rating

$-0.03$

0.03

0.24

$(0.44)$

Multidisciplinary

$-0.31^{*}$

$-0.32^{*}$

$(0.15)$

Disciplinary

$-0.45^{\star *}$

$-0.45^{\star *}$

$(0.15)$

Site 2

$-0.12$

(0.17)

Site 3

0.17

(0.18)

Site 4

0.14

(0.22)

\begin{tabular}{|c|c|c|c|}
\hline Constant & 4.35 & $4.27^{\star}$ & 3.07 \\
\hline$(2.46)$ & $(1.88)$ & $(2.44)$ & \\
\hline Adjusted $\mathrm{R}^{2}$ & -0.10 & 0.37 & 0.40 \\
\hline F Statistic & $0.005(\mathrm{df}=1 ; 10)$ & $\begin{array}{l}3.14^{\star} \\
(\mathrm{df}=3 ; \\
8)\end{array}$ & $\begin{array}{l}2.24 \\
(\mathrm{df}=6 ; \\
5)\end{array}$ \\
\hline
\end{tabular}

Note:

${ }^{*} p<.10,{ }^{* *} p<.05,{ }^{* *} p<0.01$

In model 3, we control for the variation of the different sites and still see the significant and negative multidisciplinary and disciplinary effects.

\section{Discussion And Conclusion}

Although the promise of co-production to address urban environmental challenges is compelling and research in this area has grown tremendously, concerns and challenges abound. Scholars question the 
gap between co-produced knowledge and implementation in practice, how power is balanced and traditionally marginalized actors are empowered, and the applicability of co-production frameworks beyond the context in which they are implemented (Lemos et al. 2018; Wyborn et al. 2019; Belcher et al. 2019). Broad conversations exist around evaluation of co-production processes (Wall et al. 2017) and, somewhat uncritically, the literature suggests that co-production will lead to positive outcomes (Lemos et al. 2018) but few long-term assessments of scientific and societal impacts exist.

SUSE5 intentionally designed many of the key inputs for successful co-production (as discussed by (Wall et al. 2017; Norström et al. 2020a): The research teams included the necessary scientific disciplines, significant time was explicitly set aside for collaborative team work, targeted community members with site specific local knowledge expertise were participants and integrated at the start of the process, and the process was goal-oriented and context-based. Although limited in scope and scale making broader generalizations difficult, SUSE5 did facilitate a transdisciplinary co-production process that can be compared to disciplinary and multi-disciplinary teams. Two key take-aways include: (1) the solutions proposed by the transdisciplinary co-production teams were rated higher and, (2) among the transdisciplinary co-production teams, there was significant variation between ratings of the process.

The "solution output" that co-production SUSE teams developed were rated higher than their multidisciplinary and disciplinary team peers (Table 4). Solutions that came from the transdisciplinary coproduction teams were broader in scope and included social marketing ("brand the creek"), environmental justice (suggestions that the watershed protection department could fund the equity office to be included in projects), and community engagement (and using projects to build neighborhood cohesion) considerations. Contrasted with disciplinary and multi-disciplinary teams, the solutions presented merged "ideas, norms, practices, and discourses" and "united ways of knowing and acting" (Wyborn et al. 2019) in ways that combined engineering and biological perspectives with equity and community. In this context, the co-production teams did demonstrate the promise of co-production to offer integrated solutions to complex problems.

It is difficult to know if the solutions generated by transdisciplinary co-production teams were "better" by more traditional economic (cost-benefit) or engineering standards. However, we do know that they were, on average, subjectively rated as better solutions to different urban stream problems considered. This aligns with existing theory and literature that suggest co-production processes lead to pragmatic, tangible, and proximate solutions that have broader public support since they include those affected by resulting recommendations in the process (Jagannathan et al. 2020).

As such, the findings from Hypothesis 1 help us make the connection between the co-production processes and operating context within which the solution exists. In many cases, the engineering intervention should work; the technical performance should meet the criteria as determine through plans. However, all too often, municipal design exercises consider the operating environment out of scope. Ultimately, the intervention is placed in a community and low levels of community support can make a project fail because the community may not have the institutional knowledge, workforce available, or 
motivation to operate and maintain the engineering intervention as anticipated during planning and design phases. On the contrary, when solutions are co-produced early alignment of local values and preferences with technical needs are considered in the intervention allowing the solution to be more widely adopted and sustainably fit within the fabric of community-i.e., the operating environment. The co-produced solutions are likely deemed more appropriate, as captured in Hypothesis 1, as these considerations are built in to the solution, creating a tailored alternative that meets the engineering and natural system needs while aligning with the community vision.

However, getting to the solutions was not easy for all of the transdisciplinary teams as indicated by process score variation (Fig. 4). Transdisciplinary teams had higher variability in all stages of the process (indicated by standard deviations in Table 4). This is consistent with team science literature that emphasizes effective teamwork and collaboration is based on three influencing conditions: composition, culture, and context (Salas et al. 2015). Difference in knowledge, skills, and attitudes (composition), situational characteristics that influence the meaning of behavior (context), and assumptions about an individual's values, beliefs, norms, etc. (culture) are known barriers to team interaction. One explanation is that in some groups certain participants held more tightly to socio-cultural biases excluding nontraditional participants or actively shaped the process to be aligned with their perspective. It may be that trust was slow or didn't develop or that alignment of the problem or solution never occurred. Another possibility is that a common vocabulary and understanding of the task at hand and the mechanics of the exercise may take longer to develop in transdisciplinary teams.

Other possible explanations include the different facilitation and/or leadership styles that emerged in the teams. We don't know for sure what explains this variation but known challenges around power, value conflicts, and conflicting worldviews can provide some insights. Generally, co-production aspires to empower traditionally marginalized actors and democratize expertise although more attention has recently been given to the role of power is shaping process and outcomes (Turnhout et al. 2020).

The multidisciplinary teams had the highest overall process scores. Disciplinary and multidisciplinary teams likely had more initial convergence around technical knowledge content and the relationship between individual knowledge components, an important factor or team success (Cassidy and Stanley 2019). On the other hand, when co-designing solutions with communities and engaging in participatory processes, values and priorities can differ. Consequentially, the feasible solution space can look different when considering not only these technical solutions, but tradeoffs required to meet other priorities that exist within this unique operating environment. Dialogue to reconcile these differing value systems as they manifest in solutions is likely not as streamlined as it might be when all members come from the same or similar disciplinary backgrounds. Interestingly, for all team types, the process was rated the highest after the problem structuring and identifying objectives (stage 2).

Although hard to generalize beyond the SUSE context, our results provide evidence to better understand the process and outcomes associated with co-production as it relates to urban stream issues. That said, our findings are constrained by limitations of our data and design. First, our framing of co-production is 
limited to what Jagannathan et al. (2020) refer to as scope 1 outcomes related to understanding, utilization, action, and community with little to no acknowledgement of scope 2 outcomes related to broader transformative or radical changes to the science-society relationship. Second, although each type of team worked on each site, there is variability in the complexity of the problem at each site that may have been an influence on the process and/or solution rating (although site is controlled for in Table 4, Model 3). It may be the complexity of the site or other exogenous variables that helps explain the variation in process ratings of the transdisciplinary co-production teams. Third, although the configuration of teams in disciplinary and multidisciplinary teams attempted to group participants given their self-reported background, the reality is that many do have multidisciplinary backgrounds and may wear 'more than one disciplinary hat' when examining problems and ideating solutions. Therefore, the separation of 'disciplinary' and 'multidisciplinary' may not be as clean as desired. Lastly, the "controlled" environment of SUSE is not how co-production and community-engaged processes play out in actual municipal planning projects.

\section{Declarations}

Funding: This research received no internal or external funding support; Availability of data and material (data transparency): available upon request; Code availability: $\mathrm{R}$ code available upon request; Authors' contributions: Bixler research design, analysis, writing; Belaire research design and analysis; Faust research design, analysis, writing; Scoggins research design and overall support; Gonzales research design and overall support; Ethics approval: The University of Texas Institutional Review Board was consulted prior to this project. The project was deemed a case study and not applicable for IRB review.

Consent to participate: Not applicable given case study status.

\section{References}

Bai X, Dawson RJ, Ürge-Vorsatz D, et al (2018a) Six research priorities for cities and climate change. Nature 555:23-25. https://doi.org/10.1038/d41586-018-02409-z

Bai X, Elmqvist T, Frantzeskaki N, et al (2018b) New Integrated Urban Knowledge for the Cities We Want. In: Elmqvist T, Bai X, Frantzeskaki N, et al. (eds) Urban Planet, 1st edn. Cambridge University Press, pp $462-482$

Bai X, Surveyer A, Elmqvist T, et al (2016) Defining and advancing a systems approach for sustainable cities. Current Opinion in Environmental Sustainability 23:69-78.

https://doi.org/10.1016/j.cosust.2016.11.010

Belcher BM, Claus R, Davel R, Ramirez LF (2019) Linking transdisciplinary research characteristics and quality to effectiveness: A comparative analysis of five research-for-development projects. Environmental Science \& Policy 101:192-203. https://doi.org/10.1016/j.envsci.2019.08.013 
Bixler RP, Atshan S, Banner JL, et al (2019a) Assessing integrated sustainability research: use of social network analysis to evaluate scientific integration and transdisciplinarity in research networks. Current Opinion in Environmental Sustainability 39:103-113. https://doi.org/10.1016/j.cosust.2019.08.001

Bixler RP, Lieberknecht K, Leite F, et al (2019b) An Observatory Framework for Metropolitan Change: Understanding Urban Social-Ecological-Technical Systems in Texas and Beyond. Sustainability 11:3611. https://doi.org/10.3390/su11133611

Cassidy SA, Stanley DJ (2019) Getting From 'Me' to 'We': Role Clarity, Team Process, and the Transition From Individual Knowledge to Shared Mental Models in Employee Dyads. Canadian Journal of Administrative Sciences / Revue Canadienne des Sciences de l'Administration 36:208-220. https://doi.org/10.1002/cjas.1493

Cooke NJ, Hilton ML, National Research Council (U. S.). Committee on the Science of Team Science, et al (2015) Enhancing the Effectiveness of Team Science. National Academies Press, Washington

Delice F, Rousseau M, Feitosa J (2019) Advancing Teams Research: What, When, and How to Measure Team Dynamics Over Time. Front Psychol 10:. https://doi.org/10.3389/fpsyg.2019.01324

Fiore SM (2008) Interdisciplinarity as Teamwork: How the Science of Teams Can Inform Team Science. Small Group Research 39:251-277. https://doi.org/10.1177/1046496408317797

Grimm NB, Faeth SH, Golubiewski NE, et al (2008) Global Change and the Ecology of Cities. Science 319:756-760

Jagannathan K, Arnott JC, Wyborn C, et al (2020) Great expectations? Reconciling the aspiration, outcome, and possibility of co-production. Current Opinion in Environmental Sustainability 42:22-29. https://doi.org/10.1016/j.cosust.2019.11.010

Keeler BL, Hamel P, McPhearson T, et al (2019) Social-ecological and technological factors moderate the value of urban nature. Nature Sustainability 2:29-38. https://doi.org/10.1038/s41893-018-0202-1

Lang DJ, Wiek A, Bergmann M, et al (2012) Transdisciplinary research in sustainability science: practice, principles, and challenges. Sustain Sci 7:25-43. https://doi.org/10.1007/s11625-011-0149-x

Lemos MC, Arnott JC, Ardoin NM, et al (2018) To co-produce or not to co-produce. Nature Sustainability 1:722. https://doi.org/10.1038/s41893-018-0191-0

Miller CA, Wyborn C (2020) Co-production in global sustainability: Histories and theories. Environmental Science \& Policy 113:88-95. https://doi.org/10.1016/j.envsci.2018.01.016

Milojević S (2014) Principles of scientific research team formation and evolution. PNAS 111:3984-3989. https://doi.org/10.1073/pnas.1309723111 
Nagy E, Ransiek A, Schäfer M, et al (2020) Transfer as a reciprocal process: How to foster receptivity to results of transdisciplinary research. Environmental Science \& Policy 104:148-160.

https://doi.org/10.1016/j.envsci.2019.11.007

Nancarrow SA, Booth A, Ariss S, et al (2013) Ten principles of good interdisciplinary team work. Hum Resour Health 11:19. https://doi.org/10.1186/1478-4491-11-19

Norström AV, Cvitanovic C, Löf MF, et al (2020a) Principles for knowledge co-production in sustainability research. Nature Sustainability 3:182-190. https://doi.org/10.1038/s41893-019-0448-2

Norström AV, Cvitanovic C, Löf MF, et al (2020b) Principles for knowledge co-production in sustainability research. Nat Sustain 1-9. https://doi.org/10.1038/s41893-019-0448-2

Pohl C (2008) From science to policy through transdisciplinary research. Environmental Science \& Policy 11:46-53. https://doi.org/10.1016/j.envsci.2007.06.001

Pohl C, Hadorn GH (2007) Principles for Designing Transdisciplinary Research. Oekom Verlag GmbH, Munich

Salas E, Shuffler ML, Thayer AL, et al (2015) Understanding and Improving Teamwork in Organizations: A Scientifically Based Practical Guide. Human Resource Management 54:599-622.

https://doi.org/10.1002/hrm.21628

Salas E, Stagl KC, Burke CS (2005) 25 Years of Team Effectiveness in Organizations: Research Themes and Emerging Needs. In: International Review of Industrial and Organizational Psychology 2004. John Wiley \& Sons, Ltd, pp 47-91

Turnhout E, Metze T, Wyborn C, et al (2020) The politics of co-production: participation, power, and transformation. Current Opinion in Environmental Sustainability 42:15-21.

https://doi.org/10.1016/j.cosust.2019.11.009

United Nations (2018) World Urbanization Prospects. The 2018 Revision.

Wall TU, Meadow AM, Horganic A (2017) Developing Evaluation Indicators to Improve the Process of Coproducing Usable Climate Science. Weather, Climate, and Society 9:95-107.

https://doi.org/10.1175/WCAS-D-16-0008.1

White DD, Lawless KL, Vivoni ER, et al (2019) Co-Producing Interdisciplinary Knowledge and Action for Sustainable Water Governance: Lessons from the Development of a Water Resources Decision Support System in Pernambuco, Brazil. Global Challenges 3:1800012. https://doi.org/10.1002/gch2.201800012

Wyborn C, Datta A, Montana J, et al (2019) Co-Producing Sustainability: Reordering the Governance of Science, Policy, and Practice. Annual Review of Environment and Resources 44:319-346.

https://doi.org/10.1146/annurev-environ-101718-033103 
Figures

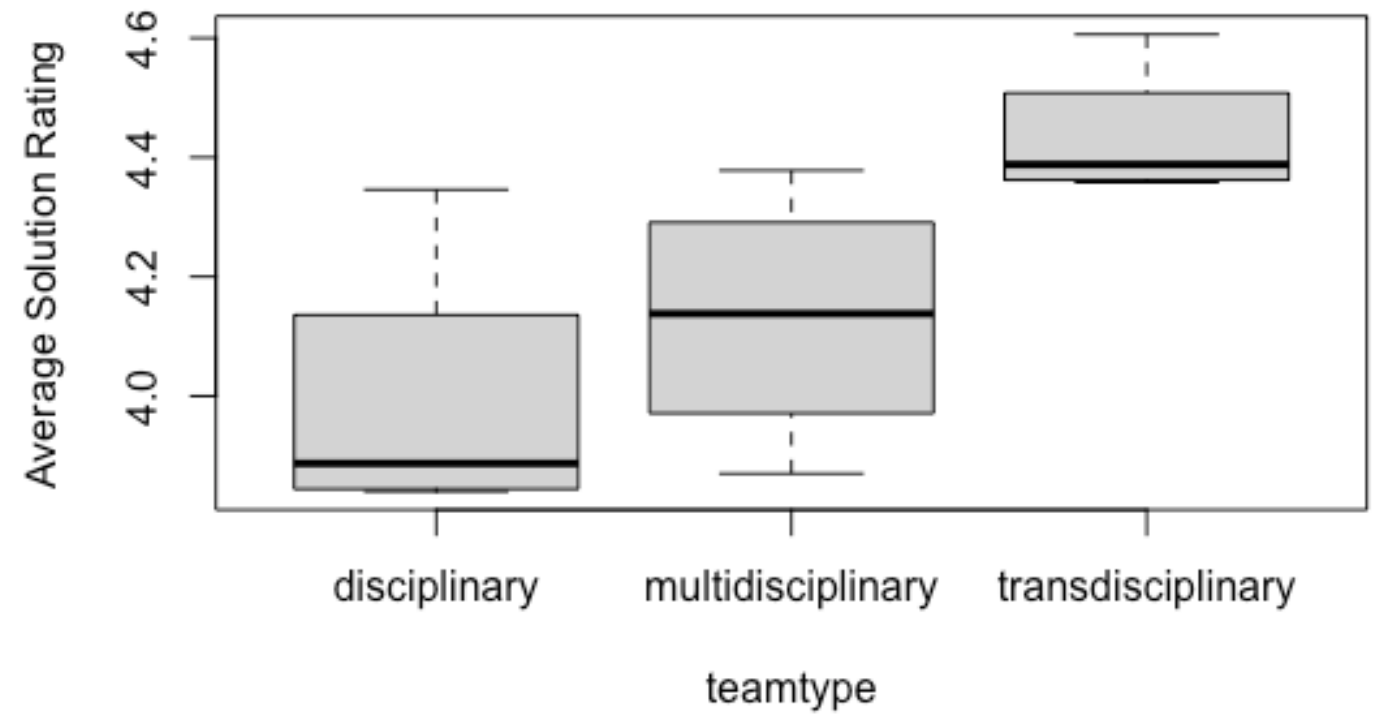

Figure 1

Average rating of solutions by team type 


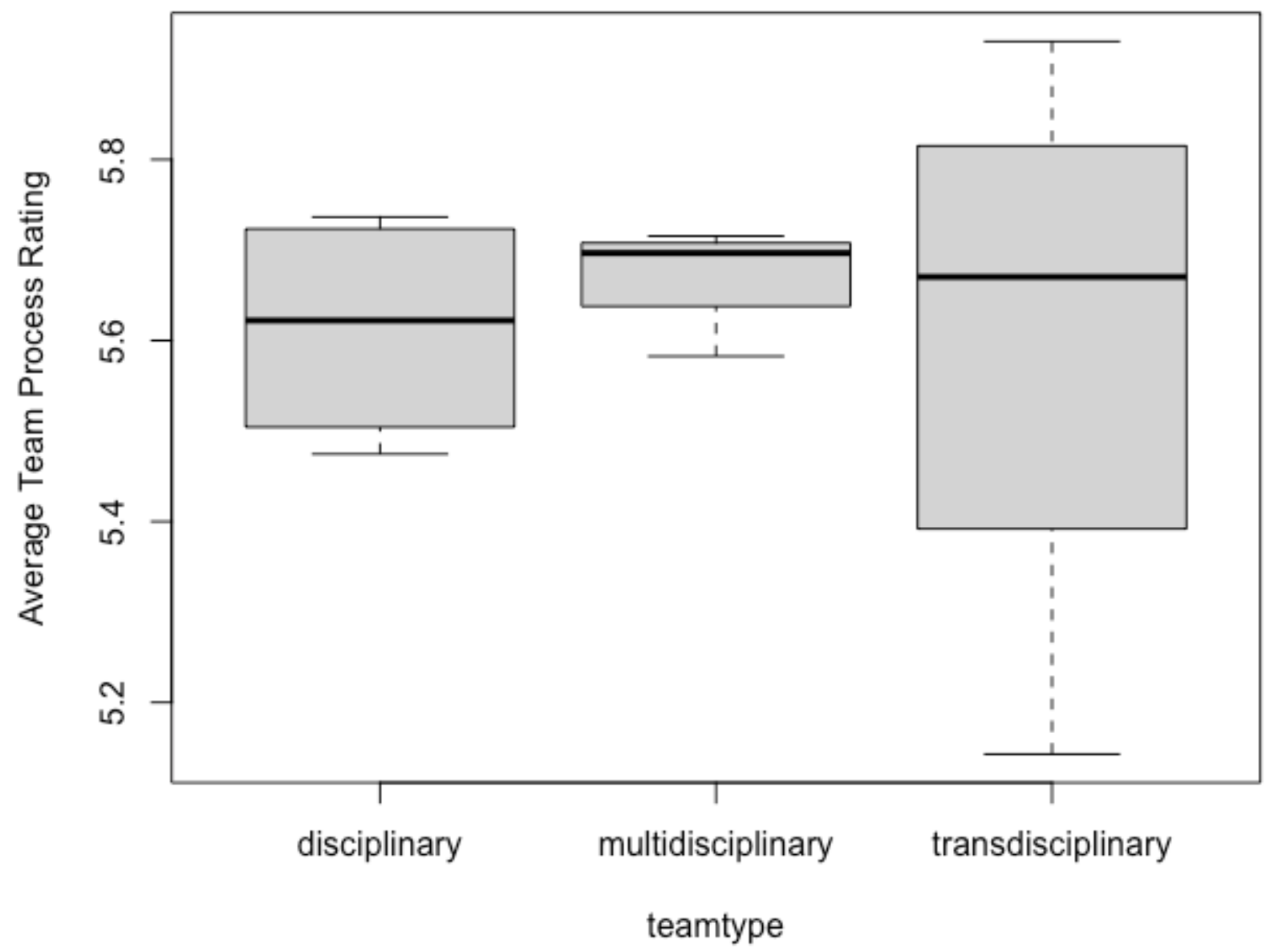

Figure 2

Average rating of internal team process by team types 


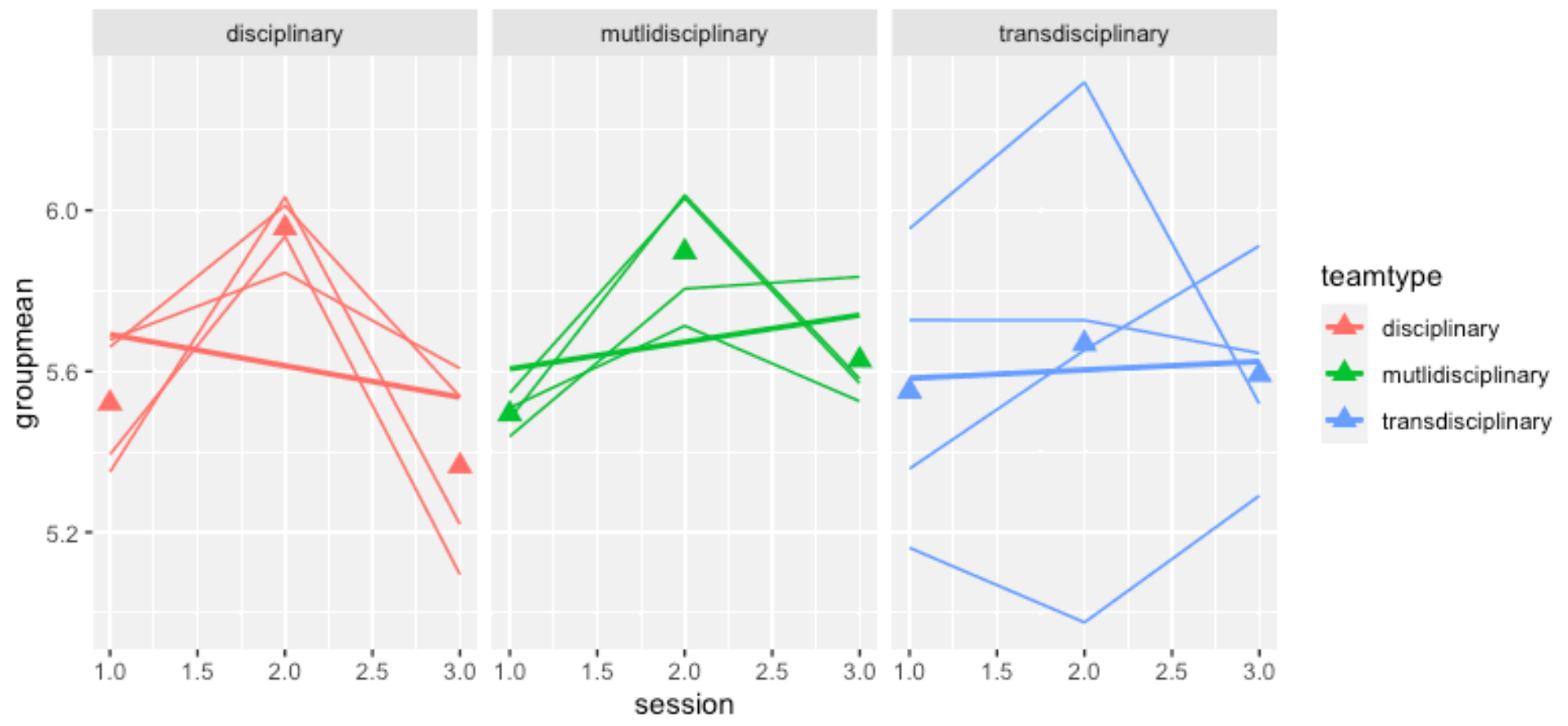

Figure 3

Ratings of the process by group and by stage 